\title{
Renal matrix Gla protein expression increases progressively with CKD and predicts renal outcome
}

Citation for published version (APA):

Miyata, K. N., Nast, C. C., Dai, T., Dukkipati, R., LaPage, J. A., Troost, J. P., Schurgers, L. J., Kretzler, M., \& Adler, S. G. (2018). Renal matrix Gla protein expression increases progressively with CKD and predicts renal outcome. Experimental and Molecular Pathology, 105(1), 120-129.

https://doi.org/10.1016/j.yexmp.2018.07.001

Document status and date:

Published: 01/08/2018

DOI:

10.1016/j.yexmp.2018.07.001

Document Version:

Publisher's PDF, also known as Version of record

Document license:

Taverne

Please check the document version of this publication:

- A submitted manuscript is the version of the article upon submission and before peer-review. There can be important differences between the submitted version and the official published version of record.

People interested in the research are advised to contact the author for the final version of the publication, or visit the DOI to the publisher's website.

- The final author version and the galley proof are versions of the publication after peer review.

- The final published version features the final layout of the paper including the volume, issue and page numbers.

Link to publication

\footnotetext{
General rights rights.

- You may freely distribute the URL identifying the publication in the public portal. please follow below link for the End User Agreement:

www.umlib.nl/taverne-license

Take down policy

If you believe that this document breaches copyright please contact us at:

repository@maastrichtuniversity.nl

providing details and we will investigate your claim.
}

Copyright and moral rights for the publications made accessible in the public portal are retained by the authors and/or other copyright owners and it is a condition of accessing publications that users recognise and abide by the legal requirements associated with these

- Users may download and print one copy of any publication from the public portal for the purpose of private study or research.

- You may not further distribute the material or use it for any profit-making activity or commercial gain

If the publication is distributed under the terms of Article $25 \mathrm{fa}$ of the Dutch Copyright Act, indicated by the "Taverne" license above, 


\title{
Renal matrix Gla protein expression increases progressively with CKD and predicts renal outcome
}

\author{
Kana N. Miyata ${ }^{\mathrm{a}, *}$, Cynthia C. Nast ${ }^{\mathrm{b}}$, Tiane Dai ${ }^{\mathrm{a}}$, Ramanath Dukkipati ${ }^{\mathrm{a}}$, Janine A. LaPage ${ }^{\mathrm{a}}$, \\ Jonathan P. Troost ${ }^{\mathrm{c}}$, Leon J. Schurgers ${ }^{\mathrm{d}}$, Matthias Kretzler ${ }^{\mathrm{e}}$, Sharon G. Adler ${ }^{\mathrm{a}}$ \\ ${ }^{a}$ Division of Nephrology and Hypertension, Los Angeles Biomedical Research Institute, Harbor-UCLA Medical Center, 1124 W. Carson Street, Torrance, CA 90502, USA \\ b Department of Pathology, Cedars-Sinai Medical Center, 8700 Beverly Boulevard, Los Angeles, CA 90048, USA \\ ${ }^{\mathrm{c}}$ Division of Nephrology, Department of Pediatrics \& Communicable Diseases, C.S. Mott Children's Hospital, University of Michigan, 1540 E Hospital Dr SPC 4259 , Ann \\ Arbor, MI 48109, USA \\ d Department of Biochemistry, Cardiovascular Research Institute Maastricht (CARIM), Maastricht University, PO Box 616, 6200, MD, Maastricht, the Netherlands \\ e Division of Nephrology, Department of Internal Medicine, University of Michigan, 1560 MSRB II, 1150 West Medical Center Drive, SPC5676, Ann Arbor, MI 48109, USA
}

\section{A R T I C L E I N F O}

\section{Keywords:}

Matrix gla protein

Chronic kidney disease

Gene expression

Vitamin K

Renal outcome

\begin{abstract}
A B S T R A C T
Background: Matrix Gla Protein (MGP) is a potent inhibitor of ectopic calcification and modulates bone morphogenesis. Little is known about MGP expression or function in kidney.

Methods: We investigated renal MGP expression in Sprague-Dawley rats after 5/6 nephrectomy (5/6 Nx) and in human kidney biopsies in the Nephrotic Syndrome Study Network (NEPTUNE) cohort. We analyzed associations between glomerular ( $n=182)$ and tubulointerstitial (TI) $(n=219)$ MGP mRNA levels and the disease activity/histologic features in NEPTUNE patients. Additionally, uncarboxylated and carboxylated MGP (ucMGP and cMGP, respectively) were localized by immunohistochemistry and quantitated in kidney tissues of patients at different stages of CKD $(n=18)$.

Results: Renal MGP expression was increased in rats after 5/6 Nx. In NEPTUNE data, baseline estimated glomerular filtration rate (eGFR) negatively correlated with glomerular and TI MGP expression $(p<0.001)$. TI MGP expression strongly correlated with interstitial fibrosis, tubular atrophy, acute tubular injury, and interstitial inflammation, independent of eGFR. Kaplan-Meier analysis and multivariable Cox regression showed that higher levels of TI MGP expression were associated with an increased risk for the composite of $40 \%$ decline in eGFR and end-stage renal disease (ESRD) (HR, 3.31; 95\% CI, 1.31 to 6.32; $p=0.02$ ). Glomerular and tubulointerstitial cells demonstrated nuclear and cytoplasmic cMGP and ucMGP staining, and eGFR inversely correlated with quantified glomerular cMGP staining $(p<0.05)$.

Conclusions: Our data demonstrate that renal MGP expression is increased in human and experimental CKD, and is associated with renal outcome. Additional studies are needed to determine its mechanism of action.
\end{abstract}

\section{Introduction}

In an unpublished study in rats 2 days, 2 weeks, and 4 weeks after 5/6 nephrectomy $(5 / 6 \mathrm{Nx})$, we noted changes in the remnant kidney in several transcripts that are prominent in bone remodeling and calcification. Early experimental studies indicated that renal calcification may accelerate chronic kidney disease (CKD) progression (Lau, 1989; Cozzolino et al., 2002; Ibels et al., 1978). While several studies reported increased renal calcium content (Gimenez et al., 1987; Ibels et al., 1981) and microscopic nephrocalcinosis (Evenepoel et al., 2015) in human kidneys in advanced CKD, the idea of a direct effect of calcification on progressive CKD in humans has been largely abandoned. Nevertheless, these changes in boneassociated proteins raise the possibility that "ossification", considered as de novo or altered expression of bone-related proteins in injured renal tubules may occur in CKD.

Matrix Gla Protein (MGP), a vitamin K-dependent protein, has attracted increasing attention as a key molecular player in inhibiting vascular calcification. Although first isolated from bone, MGP mRNA is expressed in various tissues, including heart, lung, kidney, skin, and arterial vessel walls (Schurgers et al., 2013; Wei et al., 2018a). It is synthesized by chondrocytes, vascular smooth muscle cells (VSMCs), endothelial cells, fibroblasts and leukocytes including macrophages and T-lymphocytes (Schurgers et al., 2013; Viegas et al., 2017). MGP knockout mice die within 2 months from blood vessel rupture due to extensive vascular mineralization (Luo et al., 1997). Studies have suggested that calcified VSMCs in human atherosclerotic plaques upregulate MGP gene expression

\footnotetext{
* Corresponding author.

E-mail address: kananoshiro@gmail.com (K.N. Miyata).
} 
in a negative feedback manner (Shanahan et al., 1994; Proudfoot et al., 1998; Wei et al., 2018b). To attain its full calcification inhibitory activity, MGP undergoes two post-translational modifications: serine phosphorylation and glutamate carboxylation (Schurgers et al., 2007). The active form, carboxylated MGP (cMGP), potently inhibits arterial calcification by antagonizing bone morphogenetic protein 2 and 4, (BMP-2, -4), and by directly inhibiting calcium crystal growth (Zebboudj et al., 2002; Liao et al., 2011). cMGP is detected in intact healthy vessels. Its inactive form, uncarboxylated MGP (ucMGP) accumulates in areas of vascular calcification (Schurgers et al., 2015). ucMGP has two forms; phosphorylated ucMGP (p-ucMGP) and desphosphoryated ucMGP (dp-ucMGP). Elevated plasma dp-ucMGP level is considered a proxy for vitamin $\mathrm{K}$ deficiency (Schurgers et al., 2010; Wei et al., 2016a). Because vitamin K deficiency impairs MGP carboxylation, which contributes to the development and progression of vascular calcification, there are several clinical trials ongoing to assess vitamin $\mathrm{K}$ supplementation for the prevention of vascular calcification (Krueger et al., 2013; Holden et al., 2015; Knapen et al., 2015).

Several additional studies assessed microvascular effects of MGP, including in CKD (Wei et al., 2016b). Cross-sectional studies in CKD populations have shown that estimated glomerular filtration rate (eGFR) was inversely associated with plasma dp-ucMGP levels and positively with plasma total ucMGP levels (Schurgers et al., 2010; Wei et al., 2016a; Kurnatowska et al., 2016). In patients with eGFR $\geq 60 \mathrm{~mL} / \mathrm{min} / 1.73 \mathrm{~m}^{2}$, those with high baseline plasma dp-ucMGP levels had an increased incidence of developing eGFR $<60 \mathrm{~mL} / \mathrm{min} /$ $1.73 \mathrm{~m}^{2}$ during follow-up, implicating a renoprotective effect of active MGP (Wei et al., 2017).

Currently, little is known about renal MGP expression and function. The aim of this study was to analyze renal MGP expression, localize and quantify renal cMGP and ucMGP at different CKD stages, and explore whether renal MGP is associated with renal outcomes.

\section{Materials and methods}

\subsection{Animals}

We performed 5/6Nx $(n=9)$ on Sprague-Dawley rats, sacrificed them at 2 days, 2 weeks, or 4 weeks, and compared the expression
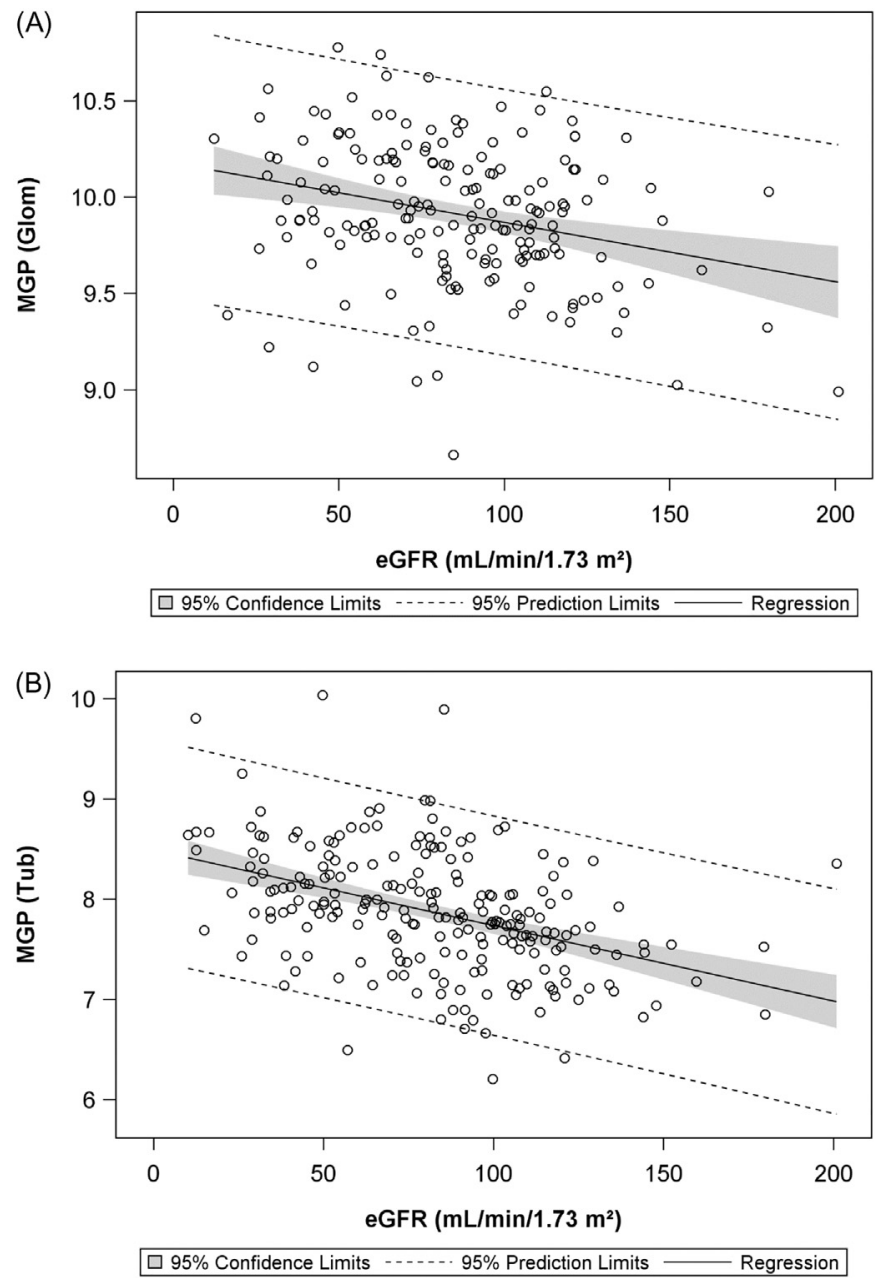

Fig. 1. Correlation of baseline eGFR $\left(\mathrm{mL} / \mathrm{min} / 1.73 \mathrm{~m}^{2}\right)$ and MGP transcript in glomeruli (A) and tubulointerstitium (B) in NEPTUNE.

Table 1

Levels of differentially expressed genes after 5/6 Nx Significant differences versus control (sham surgery), ${ }^{*} P<0.05 ; * * P<0.01$.

\begin{tabular}{|c|c|c|c|c|c|c|c|}
\hline \multirow[t]{2}{*}{ Gene Symbol } & \multirow[t]{2}{*}{ Gene Title } & \multicolumn{6}{|c|}{ Fold Changes } \\
\hline & & 2 days & & 2 weeks & & 4 weeks & \\
\hline \multicolumn{8}{|c|}{ A. Calcification Promotors } \\
\hline BMP-2 & Bone morphogenetic protein 2 & 1.7 & $* *$ & 2.35 & ** & 2.36 & $* *$ \\
\hline BMP-4 & Bone morphogenetic protein 4 & -1.96 & * & -2.08 & $* *$ & -2.76 & $* *$ \\
\hline SMAD1 & Mothers against decapentaplegic homolog 1 & 1.36 & * & 1.35 & $* *$ & 1.59 & $* *$ \\
\hline ON(SPARC) & Osteonectin & 1.21 & & 2.23 & ** & 1.61 & * \\
\hline LRP5 & Low density lipoprotein receptor-related protein 5 & 4.29 & $* *$ & 2.02 & $* *$ & 2.37 & ** \\
\hline IGFBP4 & Insulin-like growth factor binding protein 4 & -1.41 & & -2.08 & $* *$ & -1.56 & * \\
\hline TGFB1 & Transforming growth factor beta 1 & 2.06 & * & 2.69 & $* *$ & 2.66 & $* *$ \\
\hline CDH11 & Cadherin 11 & 1.03 & & 3.27 & $* *$ & 1.980 & $* *$ \\
\hline COL1a1 & Collagen type I, alpha 1 & 6.72 & $* *$ & 7.9 & ** & 4.940 & $* *$ \\
\hline FN1 & Fibronectin 1 & 5.52 & ** & 5.89 & ** & 4.720 & $* *$ \\
\hline \multicolumn{8}{|c|}{ B. Calcification Inhibitors } \\
\hline TNFRSF11B (OPG) & Osteoprotegerin & -4.96 & $* *$ & -6.04 & ** & -7.06 & $* *$ \\
\hline VNN1 & Vanin-1 & -2.2 & $* *$ & -4.46 & ** & -2.37 & $* *$ \\
\hline MGP & Matrix Gla protein & 2.16 & $* *$ & 3.27 & $* *$ & 3.31 & ** \\
\hline SSP1 (OPN) & Osteopontin & 4.99 & $* *$ & 5.66 & $* *$ & 6.03 & ** \\
\hline CSF1R & Colony stimulating factor 1 receptor & 1.74 & * & 2.95 & $* *$ & 2.9 & $* *$ \\
\hline FBN1 & Fibrillin 1 & 1.51 & & 4.71 & ** & 3.09 & $* *$ \\
\hline CTSK & Cathepsin $\mathrm{K}$ & 1.39 & & 2.71 & $* *$ & 2.59 & $* *$ \\
\hline PTGFA & Platelet-derived growth factor, alpha polypeptide & 1.71 & $* *$ & 1.83 & $* *$ & 1.82 & $* *$ \\
\hline S100A4 (FSP1) & S100 Calcium Binding Protein A4 & 4.9 & $* *$ & 4.74 & ** & 3.89 & $* *$ \\
\hline LOC498289 & Similar to Opsin 3 & 2.13 & * & 3.12 & ** & 3.08 & $* *$ \\
\hline DES & Desmin & 2.76 & $* *$ & 3.13 & $* *$ & 2.48 & ** \\
\hline
\end{tabular}



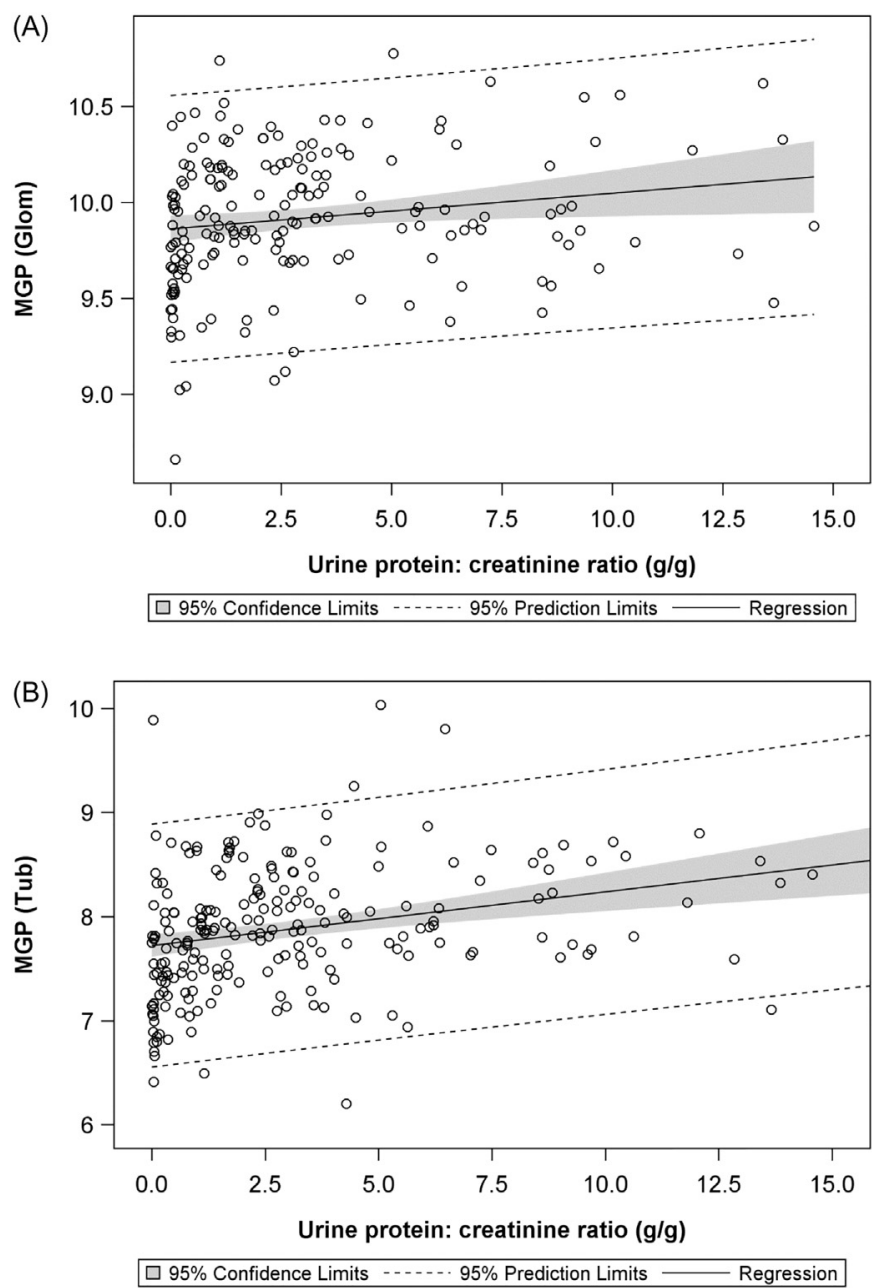

Fig. 2. Correlation of baseline UPCR $[\mathrm{g} / \mathrm{g}]$ and MGP transcript in glomeruli (A) and tubulointerstitium (B) in NEPTUNE.

results to sham-operated rats (Control, $n=3$ ). Procedures were performed according to guidelines established by the National Research Council Guide for the Care and Use of Laboratory Animals. All protocols were approved by the Animal Research Committee, Los Angeles Biomedical Research Institute.

\subsection{Gene expression array analysis}

Affymetrix Gene Chip 230_2 was used to perform expression analysis. Total RNA from three remnant kidneys at each time point and three normal kidneys were labeled and hybridized to the chips. For each gene, data were expressed as average differences between the perfect match and mismatch probes.

\subsection{Nephrotic Syndrome Study Network (NEPTUNE), patient protocol}

Glomerular and TI transcript data for MGP, and baseline and followup clinical data were obtained from the Nephrotic Syndrome Study Network (NEPTUNE). NEPTUNE is part of the National Institutes of Health (NIH) Rare Disease Clinical Research Network (RDCRN). The study design and cohort baseline description are published (Gadegbeku et al., 2013; Gipson et al., 2016). NEPTUNE was approved by collaborating center Institutional Review Boards, and subjects or guardians provided consent to participate. Eligible patients had a clinically indicated renal biopsy for suspected minimal change disease (MCD), membranous (MN), or focal and segmental glomerulosclerosis (FSGS), with proteinuria $\geq 500 \mathrm{mg}$ /day estimated from a 24 -h or spot urine
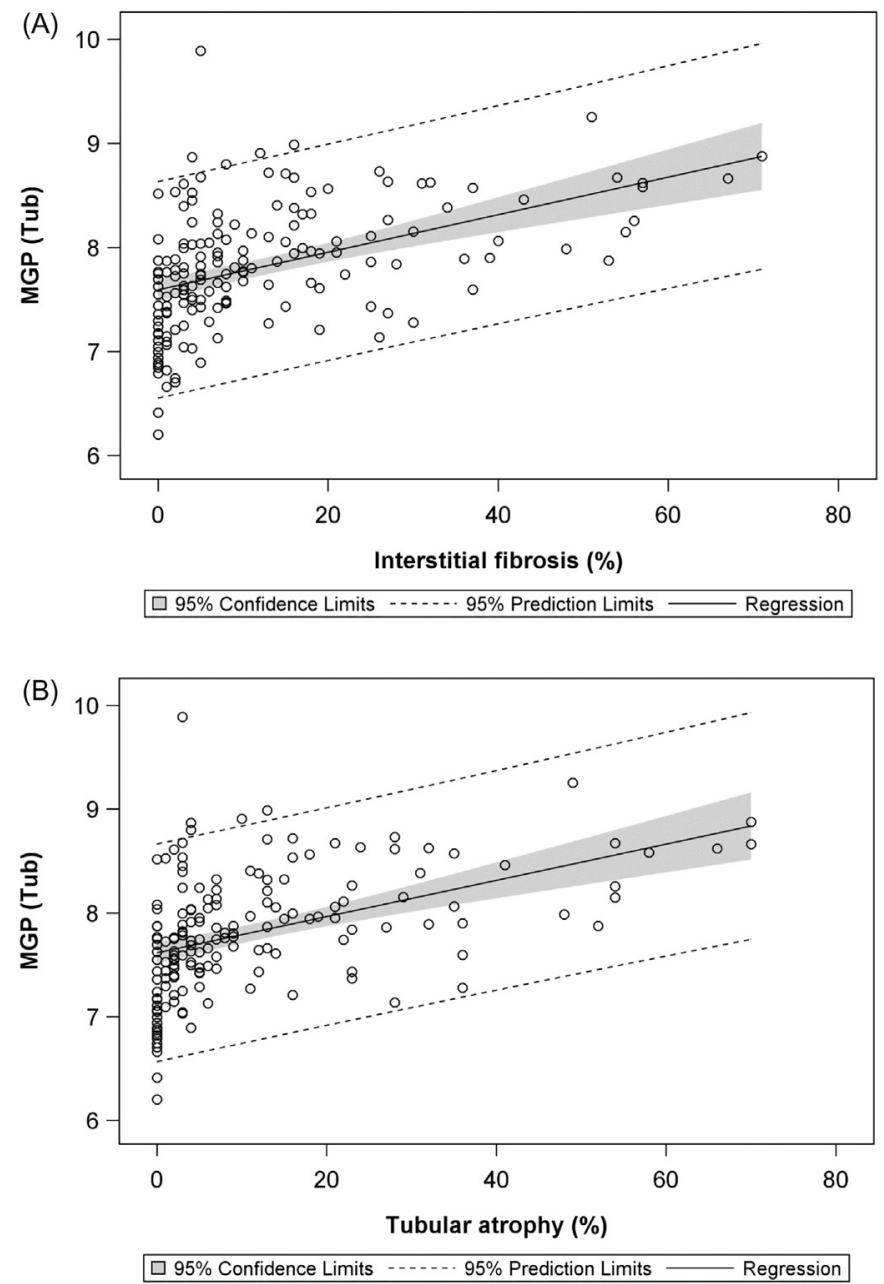

Fig. 3. Correlation between tubulointerstitial MGP transcript and interstitial fibrosis (A) and tubular atrophy (B) in NEPTUNE data.

collection and without clinical or pathologic evidence of non-targeted kidney diseases.

\subsection{NEPTUNE, morphologic assessments}

In NEPTUNE biopsies, interstitial fibrosis (IF), tubular atrophy (TA), acute tubular injury (ATI) and interstitial inflammation (II) were assessed on whole-slide images as described (Barisoni et al., 2016). Glomerular, tubular, interstitial and vascular features were evaluated by up to five participating renal pathologists, and the average score was used for each feature. Visual quantitative assessment of IF/TA and II was reported as $0-100 \%$ of cortex involved, and ATI assessment was reported as none $(0)$, mild $(1+)$, moderate $(2+)$, or severe $(3+)$.

\subsection{NEPTUNE, clinical data and outcome analysis}

Socio-demographic data and medical history were recorded, and blood and urine specimens were collected at baseline and each followup visit for up to 5 years (Hogan et al., 2015). eGFR (mL/min/1.73m ${ }^{2}$ ) was calculated using the Chronic Kidney Disease Epidemiology Collaboration (CKD-EPI) formula for participants $\geq 18$ years old and the modified CKiD-Schwartz formula for children $<18$ years old. CKD progression was evaluated with a composite of $40 \%$ decline in eGFR from baseline or end-stage renal disease (ESRD) (Mariani et al., 2017; Levey et al., 2014), defined as the initiation of dialysis, kidney transplant, or eGFR $<15 \mathrm{~mL} / \mathrm{min} / 1.73 \mathrm{~m}^{2}$ on two measurements (Gipson et al., 2016). 

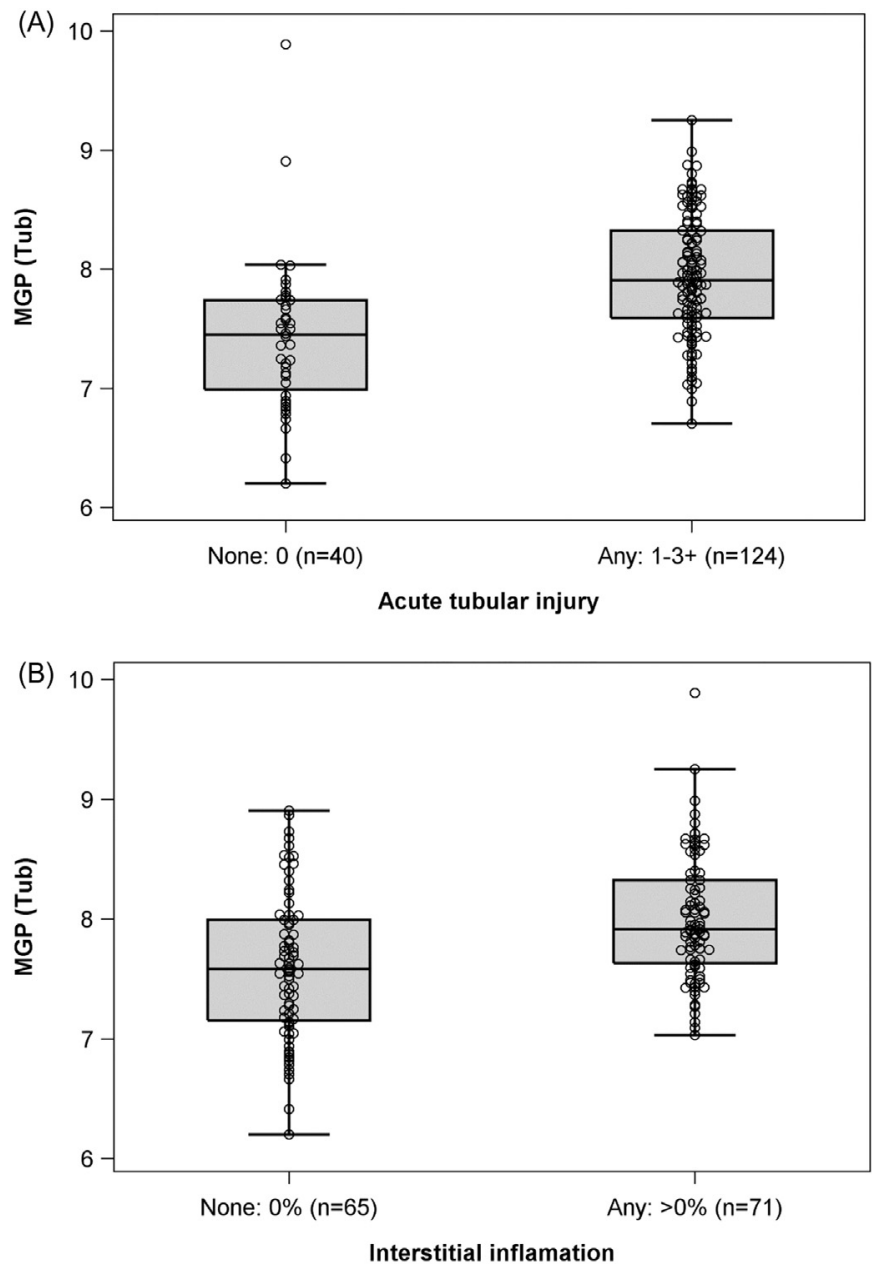

Fig. 4. Tubulointerstitial MGP transcript in biopsies with and without acute tubular injury (ATI) (A) and interstitial inflammation (B) in NEPTUNE data.

\subsection{NEPTUNE, molecular data}

Renal biopsy cores were microdissected to separate glomerular and TI compartments. Total RNA was isolated, reverse transcribed, amplified and hybridized on an Affymetrix 2.1 ST platform as described (Mariani et al., 2017; Lai et al., 2015; Schmid et al., 2006). Gene expression was normalized, quantified and annotated at the Entrez Gene level.

\section{7. cMGP and ucMGP immunohistochemistry}

To localize and quantify cMGP and ucMGP proteins, immunohistochemistry was performed on kidney tissues previously obtained for clinical reasons, including FSGS or diabetic kidney disease (DKD) biopsies with various CKD stages, and normal kidney from cancer nephrectomies for controls. This study was approved by the Los Angeles Biomedical Research Institute and Cedars-Sinai Institutional Review Boards.

Four-micron sections of formalin-fixed paraffin-embedded tissues were deparaffinized and rehydrated. Staining was performed with mouse monoclonal antibodies against cMGP and ucMGP (IDS, Boldon, UK and ref. Schurgers ATVB2005). Following antigen retrieval with $\mathrm{pH} 6$ citrate buffer at $110^{\circ} \mathrm{C}$ and blocking with $3 \% \mathrm{H}_{2} \mathrm{O}_{2}$ for $10 \mathrm{~min}$, slides were incubated with the primary antibody at 1:400 dilution overnight at $4^{\circ} \mathrm{C}$. Detection was performed using a Ventana DAB detection kit. Stained slides were scanned using an Aperio scanner and regions of interest including glomeruli, TI, arteries and arterioles were
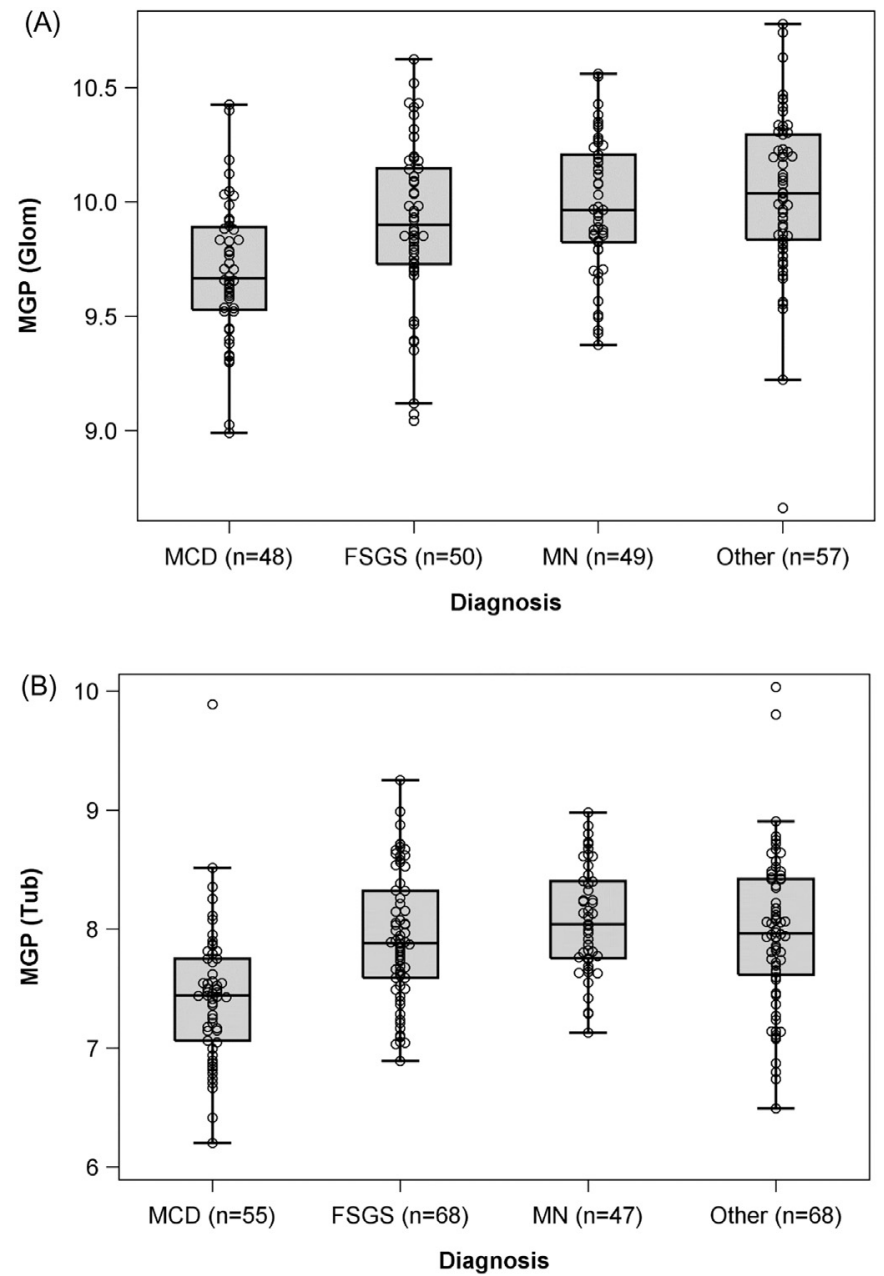

Fig. 5. Glomerular (A) and tubular (B) MGP transcripts in biopsies by diagnosis in NEPTUNE data.

MCD, minimal change disease. FSGS, focal segmental glomerulosclerosis. MN, membranous nephropathy.

annotated and analyzed separately. Staining in regions of interest was quantitated by area and by cells within the area normalized to controls. They were assessed for inflammation (0-100\%) on light microscopic slides. Biopsies also underwent Alizarin red and von Kossa staining to assess calcium deposition using a scale of $0-4+$.

\subsection{Statistical analysis}

Continuous data were reported as mean \pm standard deviation if normally distributed and as median and interquartile range (IQR) if not. Categorical data were expressed as frequencies and percentages.

Pearson's correlation coefficient was used to analyze correlation between continuous variables. Kruksal-Wallis tests were used to compare MGP expression by categorical variables.

The association of MGP expression levels with quantitated morphologic changes were explored using multivariable linear and logistic regression models adjusting for eGFR. The Kaplan-Meier method was used to estimate the time to kidney failure. Comparison between survival curves were made by log-rank test. Cox proportional hazards model was fit to estimate the hazard ratio (HR) for the composite of $40 \%$ decline in eGFR or ESRD. Backward stepwise selection of covariates was used. Covariates were selected either on the basis of whether they showed a significant association with MGP expression level in univariate analysis or whether they were known to influence the renal outcome. Analyses were performed using both STATA, v12.1(College 

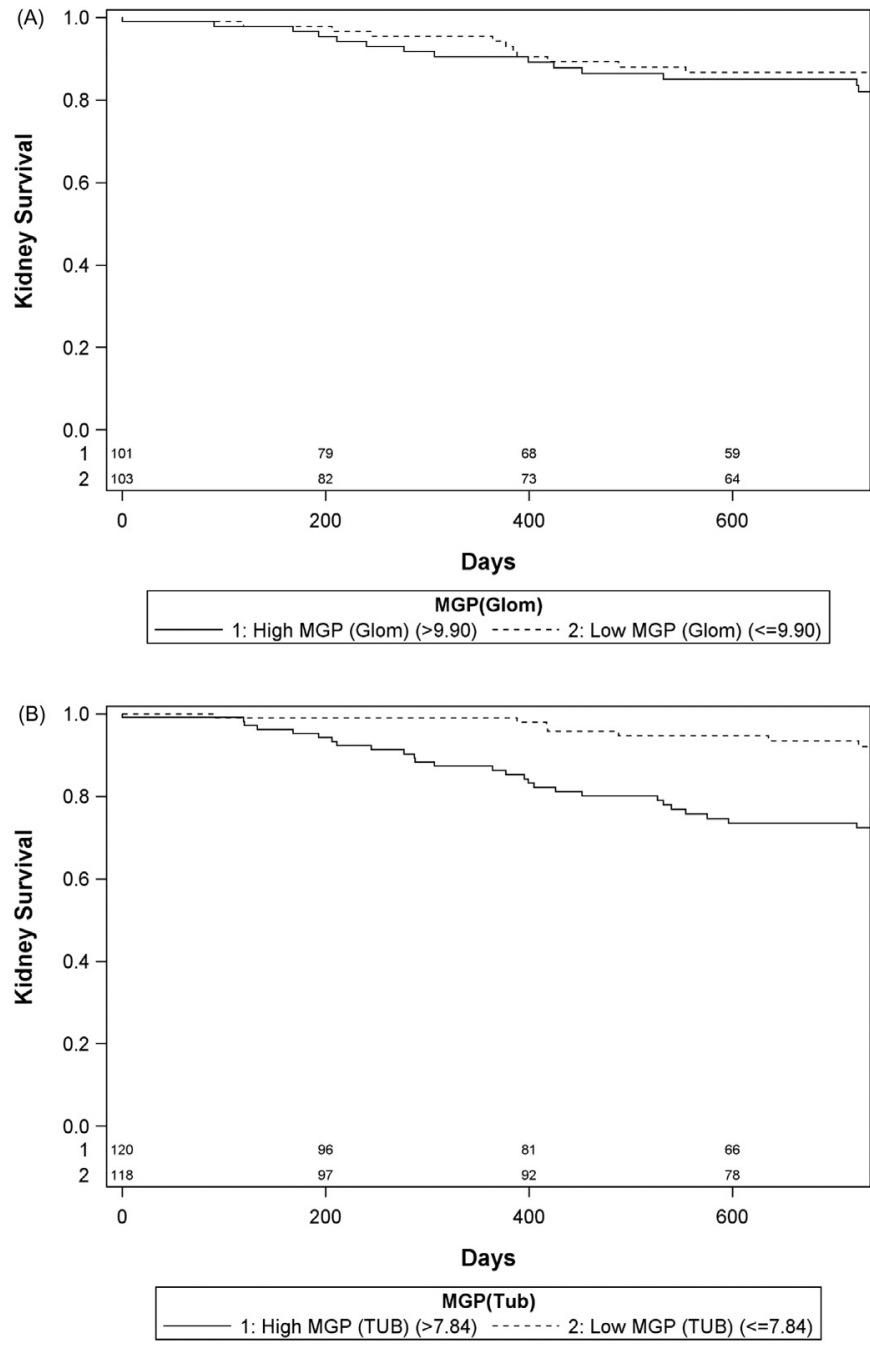

Fig. 6. Time to ESRD or $40 \%$ reduction in eGFR by glomerular (A) and tubular (B) MGP transcript in biopsies in NEPTUNE data.

Table 2

Results of Cox-proportional hazards model of tubulointerstitial (TI) MGP transcripts as a predictor of time to ESRD or $40 \%$ reduction in eGFR.

\begin{tabular}{|c|c|c|c|}
\hline & Hazard ratio & $\begin{array}{l}95 \% \text { Confidence } \\
\text { interval }\end{array}$ & $p$ \\
\hline \multicolumn{4}{|l|}{ Unadjusted } \\
\hline \multicolumn{4}{|l|}{ MGP (TI) } \\
\hline High $(>7.84)$ & 4.16 & 2.06 to 8.39 & $<0.001$ \\
\hline Low $(\leq 7.84)$ & REF & REF & REF \\
\hline \multicolumn{4}{|l|}{ eGFR adjusted } \\
\hline \multicolumn{4}{|l|}{ MGP (TI) } \\
\hline High $(>7.84)$ & 2.75 & 1.29 to 5.86 & 0.009 \\
\hline Low $(\leq 7.84)$ & REF & REF & REF \\
\hline eGFR (per 30) & 0.64 & 0.47 to 0.90 & 0.01 \\
\hline \multicolumn{4}{|l|}{$\begin{array}{l}\text { Final backwards selection } \\
\text { model }^{\mathrm{a}}\end{array}$} \\
\hline \multicolumn{4}{|l|}{ MGP (TI) } \\
\hline High $(>7.84)$ & 3.31 & 1.16 to 9.44 & 0.02 \\
\hline Low $(\leq 7.84)$ & REF & REF & REF \\
\hline UPCR (per 1) & 1.10 & 1.01 to 1.20 & 0.02 \\
\hline \multicolumn{4}{|l|}{ Race } \\
\hline Black/African American & 2.88 & 1.31 to 6.32 & 0.008 \\
\hline Other & REF & REF & REF \\
\hline $\begin{array}{l}\text { Global sclerosis (\%) (per } \\
\text { 10) }\end{array}$ & 1.24 & 1.09 to 1.42 & 0.001 \\
\hline
\end{tabular}

a Test covariates include MGP(TI), eGFR, UPCR, age, race, interstitial fibrosis, global sclerosis, immunosuppressive therapy, RAAS blockade therapy.
Station, TX, USA) and SAS 9.4 (SAS Institute Inc.,Cary, NC, USA). $p$ value of $<0.05$ was considered statistically significant.

\section{Results}

\subsection{Gene expression profiles in rat remnant kidney tissues after $5 / 6 N x$}

Differentially expressed genes related to ossification were identified in remnant kidney (Table 1). Among these, expression of MGP was significantly increased in rats after $5 / 6 \mathrm{Nx}$ as follows: 2.16 -fold (2 days, $p=0.002$ ), 3.27-fold ( 2 weeks, $p=0.0002$ ), and 3.31-fold (4 weeks, $\mathrm{p}=0.0002)$.

\subsection{MGP expression in glomerular and tubulointerstitial samples in the NEPTUNE cohort}

Genome-wide tissue mRNA expression from microdissected glomeruli and TI were analyzed separately. MGP expression was analyzed from glomeruli (182 patients; $41 \mathrm{MCD}, 48 \mathrm{FSGS}, 46 \mathrm{MN}$, and 47 others) and TI (219 patients; 49 MCD, 67 FSGS, 44 MN, and 59 others). Expression levels were correlated with baseline and follow-up laboratory data. There was a negative correlation between eGFR and both glomerular $(r=-0.28, p<0.001)$ (Fig. 1A) and TI $(r=-0.43$, $\mathrm{p}<0.001$ ) MGP transcript levels (Fig. 1B). A weaker, but still significant, negative correlation was found between baseline UPCR and glomerular $(r=0.17, p=.02)$ (Fig. 2A) and TI $(r=0.28, \mathrm{p}<0.001)$ MGP expression (Fig. 2B). This is consistent with a TI injury signal in these subjects with primary glomerular disease. Consistent with this, TI MGP transcript levels positively correlated with IF/TA (Fig. 3). MGP was more highly expressed in TI with ATI or II than those without them. (Fig. 4). A multivariable linear regression model for IF/TA and logistic regression model for ATI and II showed that TI MGP transcript levels were consistently associated with IF/TA, ATI, and II after adjusting for eGFR.

MGP expression levels did not correlate with serum calcium or phosphorus levels. Among MCD, FSGS, MN, and other glomerulopathies, the lowest expression of MGP was seen in glomeruli and TI in MCD (Fig. 5, $p<0.001$ ). This difference remained significant after adjustment for baseline eGFR.

\subsection{MGP expression and disease progression in NEPTUNE cohort}

Unadjusted Kaplan-Meier survival curves (Fig. 6) demonstrate that higher TI MGP expression was associated with an increased hazard of ESRD or $40 \%$ decline from baseline eGFR (Fig. 6B; log-rank test: $\mathrm{p}<0.001$ ). In this analysis, where the cohort was divided into two groups by the median level of TI MGP expression ( $>7.84$ or $\leq 7.84$ ), the group with the higher TI MGP expression had 36 events per 120 patients and 3876 patient-months of follow-up (risk $=11.1$ per 100 patient-years), while the group with lower TI MGP expression had 10 events per 118 patients and 3920 patient-months of follow-up. (risk $=3.06$ per 100 patient-years).

In the unadjusted Cox proportional hazards model, the group with the higher TI MGP expression had a HR of 4.16 (95\% CI, 2.06-8.39; $p<0.001$ ) for ESRD $/ 40 \%$ eGFR decline from baseline (Table 2). After adjusting for baseline eGFR, higher TI MGP expression remained a significant predictor for ESRD/40\% eGFR decline (HR, 2.75; 95\% CI, 1.29-5.86; $p=0.009$ ). The multivariable Cox regression analysis with adjustment for eGFR, UPCR, age, race, IF, global glomerulosclerosis, immunosuppressive and RAAS therapies yielded a HR of 3.31 (95\% CI, $1.31-6.32 ; p=0.02$ ) for ESRD $/ 40 \%$ eGFR decline. This result further suggests that TI MGP expression is an independent predictor of CKD progression in these glomerulopathies. 


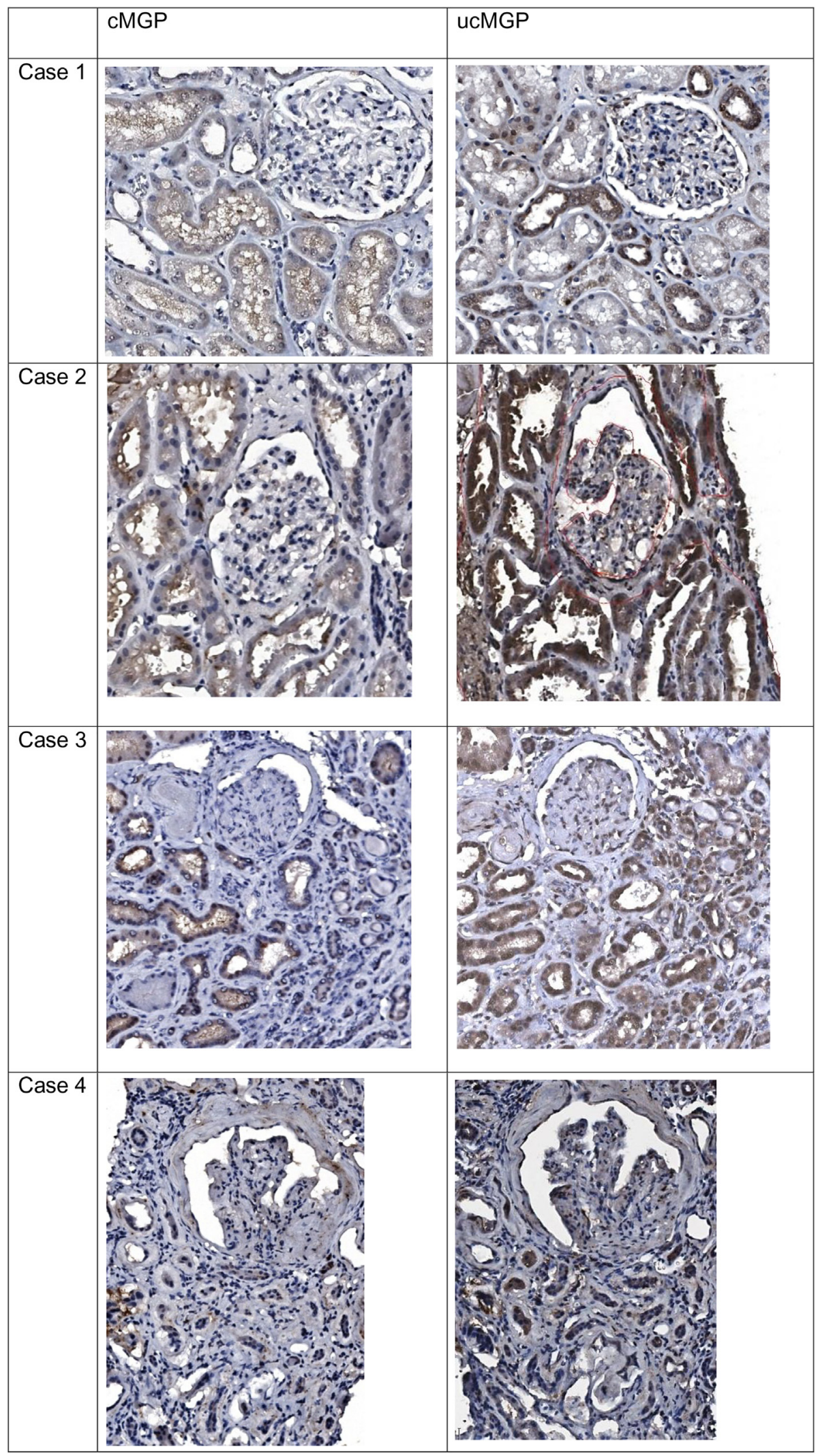

Fig. 7. Immunohistochemistry of human kidney tissues with antibodies against cMGP and ucMGP.

Case 1 (control kidney from cancer nephrectomy, eGFR $85.9 \mathrm{~mL} / \mathrm{min} / 1.73 \mathrm{~m}^{2}$, UPCR $0 \mathrm{~g} / \mathrm{g}$ ): cMGP stains proximal tubular cells luminal cytoplasm and focal apical brush borders, focal distal tubular epithelial apical cytoplasm and nuclei, and focal glomerular parietal epithelial cell nuclei. ucMGP shows weak proximal tubular cell cytoplasmic staining, strong diffuse and focal prominent apical cytoplasmic staining of distal tubular cells and weak nuclear staining of glomerular parietal and visceral epithelial cells.

Injured kidneys (Case 2. A patient with FSGS, eGFR $61 \mathrm{~mL} / \mathrm{min} / 1.73 \mathrm{~m}^{2}$, UPCR $1.0 \mathrm{~g} / \mathrm{g}$; Case 3 . A patient with FSGS, eGFR $5 \mathrm{~mL} / \mathrm{min} / 1.73 \mathrm{~m}^{2}$, UPCR $1.2 \mathrm{~g} / \mathrm{g}$; Case 4. A patient with diabetic glomerulosclerosis, eGFR $11 \mathrm{~mL} / \mathrm{min} / 1.73 \mathrm{~m}^{2}$, UPCR $21 \mathrm{~g} / \mathrm{g}$ ) show cMGP staining which persists or is increased in proximal and distal tubular cell cytoplasm of preserved tubules, reduced cytoplasmic but focal preserved or increased nuclear staining in atrophic tubules, and weak staining of glomerular extracellular matrix. Staining of glomerular epithelial cell nuclei can be seen in Case 2. Staining for ucMGP shows more intense cytoplasmic staining of non-atrophied proximal tubular cells with preserved or enhanced staining of cell cytoplasm in atrophic tubules. Patent glomeruli had more prominent staining of podocyte nuclei and sclerotic glomeruli showed weak staining of extracellular matrix material.

3.4. Clinical characteristics of patients whose kidney biopsies were stained for cMGP/ucMGP immunohistochemistry

Immunohistochemistry was performed on kidney tissue from 18 patients with different CKD stages (12 idiopathic FSGS, 4 DKD, and 2 cancer nephrectomies). The mean age and eGFR was $51.1 \pm 8.6$ years and $34.4 \pm 25.7 \mathrm{~mL} / \mathrm{min} / 1.73 \mathrm{~m}^{2}$, respectively. All baseline patient characteristics are presented in Table S1. No patients were treated with immunosuppressives or warfarin at the time of biopsy. 
(A)

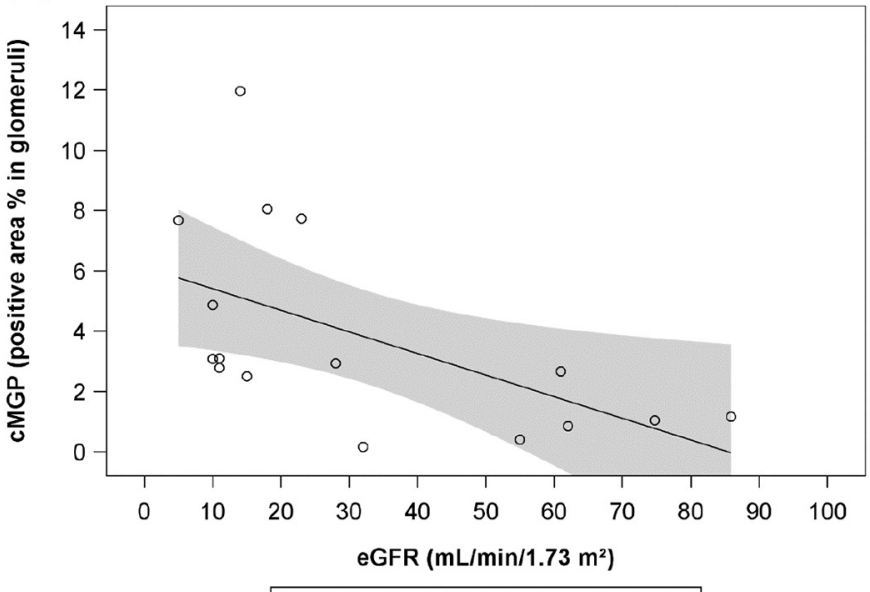

(C)

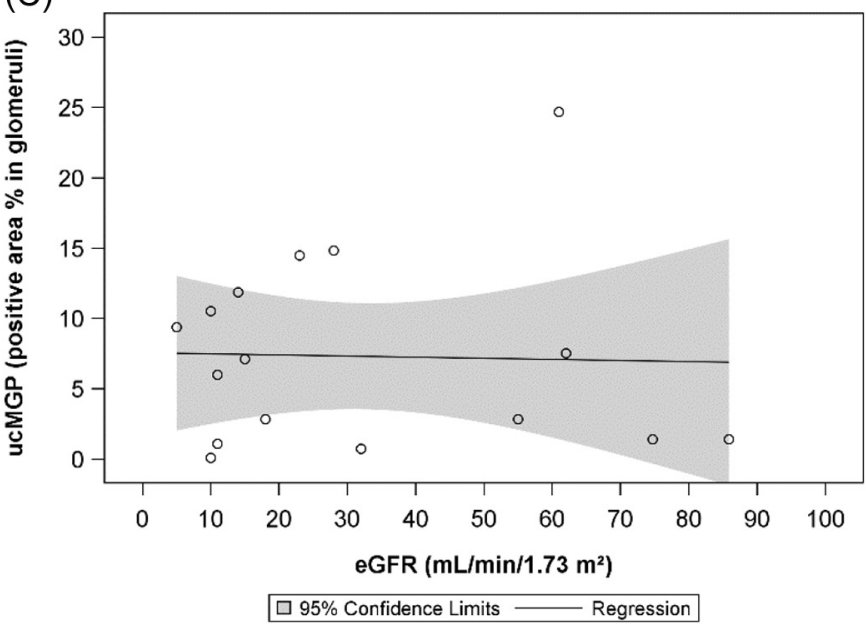

Fig. 8. Quantification of cMGP and ucMGP staining in kidney biopsies.

A. Correlation between eGFR and cMGP positive area in glomeruli.

B. Correlation between eGFR and cMGP positive area in TI.

C. Correlation between eGFR and ucMGP positive area in glomeruli.

D. Correlation between eGFR and ucMGP positive area in TI.

\subsection{Localization of $c M G P$ and $u c M G P$ in human kidney biopsies}

Fig. 7 illustrates representative staining of cMGP and ucMGP in human kidney biopsies. In control renal cortex, cMGP staining was often present in proximal tubular cell luminal cytoplasm and less often in apical brush borders, and focally in distal tubular epithelial apical cytoplasm and nuclei. There was focal weak staining of glomerular parietal epithelial cell nuclei. Arteries had positive staining in the internal elastic lamina, focally in smooth muscle cytoplasm and infrequently in endothelial cell nuclei and cytoplasm. Within the medulla, loops of Henle had apical and perinuclear cMGP while collecting ducts showed apical and focally diffuse cytoplasmic staining. In injured kidneys, there was reduced cMGP staining in atrophied tubules while sclerotic glomeruli had weak positive staining in extracellular matrix. Preserved tubules had similar to increased staining of proximal and distal tubules relative to controls, and there was enhanced nuclear and cytoplasmic staining of parietal cells in patent glomeruli.

In control renal cortical tissue, ucMGP had minimal to weak staining diffusely in proximal tubular cell cytoplasm including luminal cytoplasm, while distal tubular cells showed more intense diffuse and focal apical cytoplasmic staining. Glomerular parietal and visceral epithelial cells had weak nuclear ucMGP, and arteries showed staining of the internal elastic lamina, and in smooth muscle cells focally in the
(B)

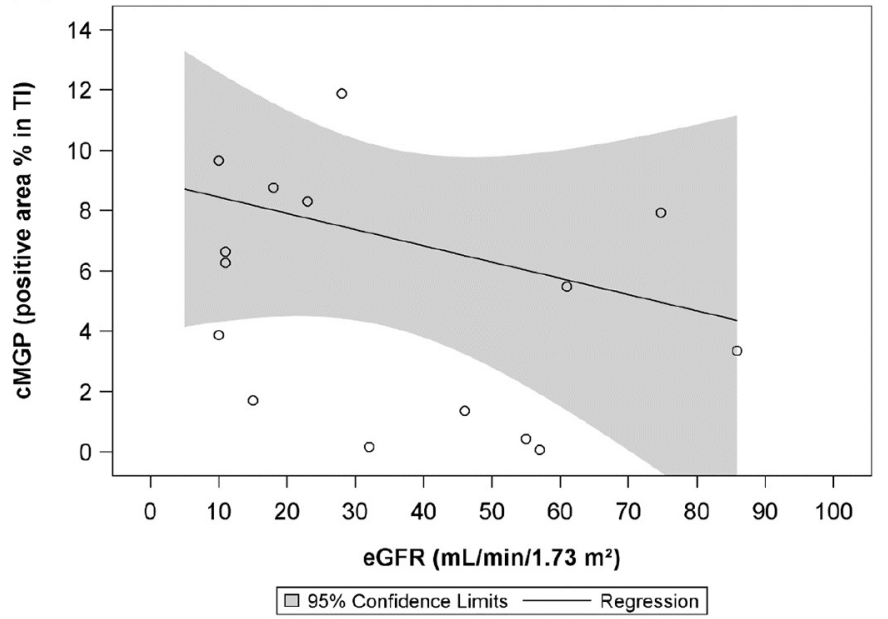

(D)

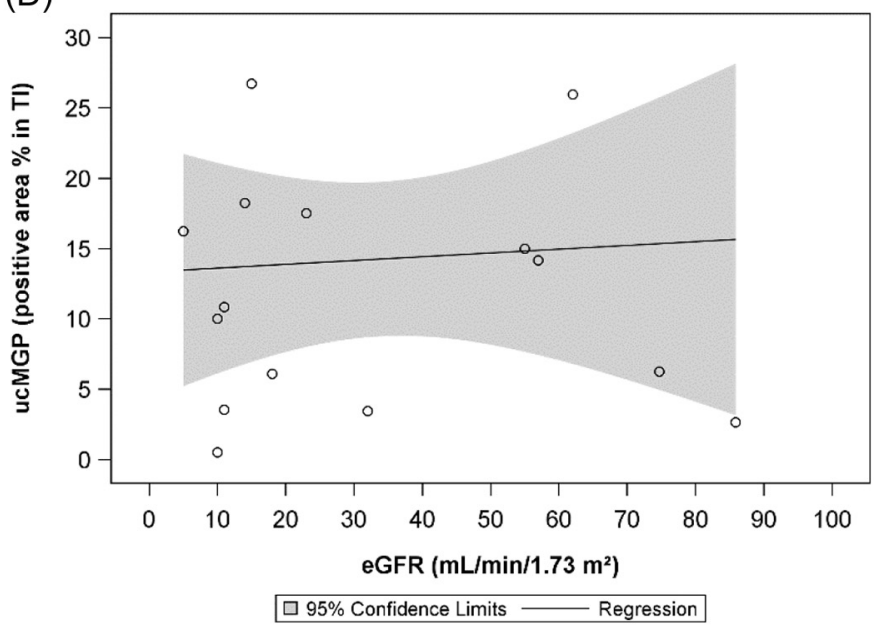

nuclei and infrequently weakly in the cytoplasm. In kidneys with chronic injury, there was more intense cytoplasmic ucMGP of nonatrophied proximal tubular cells with preserved or enhanced staining of cell cytoplasm in atrophic tubules. Patent glomeruli had more prominent staining of podocyte nuclei and sclerotic glomeruli showed weak staining of extracellular matrix material. Interestingly, there was heavy cytoplasmic staining of interstitial inflammatory cells, which was not present with cMGP.

All the biopsies were evaluated with Alizarin red and von Kossa stains and none had any calcification.

\section{6. $c M G P$ and $u c M G P$ quantification by digital immunohistochemistry}

Quantification of cMGP and ucMGP immunostaining of the 18 samples showed a negative correlation between eGFR and cMGP positive area in glomeruli $(r=-0.56, p=0.02$. Fig. $8 \mathrm{~A})$, but not in the TI. There were no significant correlations between eGFR and glomerular/TI ucMGP or combined cMGP + ucMGP positive area (Fig. 8, B-D). Likewise, no significant correlations were found between eGFR and cMGP or ucMGP positive areas in arteries. TI inflammation (\%) was not associated with cMGP, ucMGP, or cMGP + ucMGP positive areas. Neither serum calcium $(\mathrm{Ca})$, phosphorus $(\mathrm{P}), \mathrm{Ca} \times \mathrm{P}$, or alkaline phosphatase were correlated with cMGP or ucMGP positive areas, positive nuclei, or positive cytoplasm (\%). 

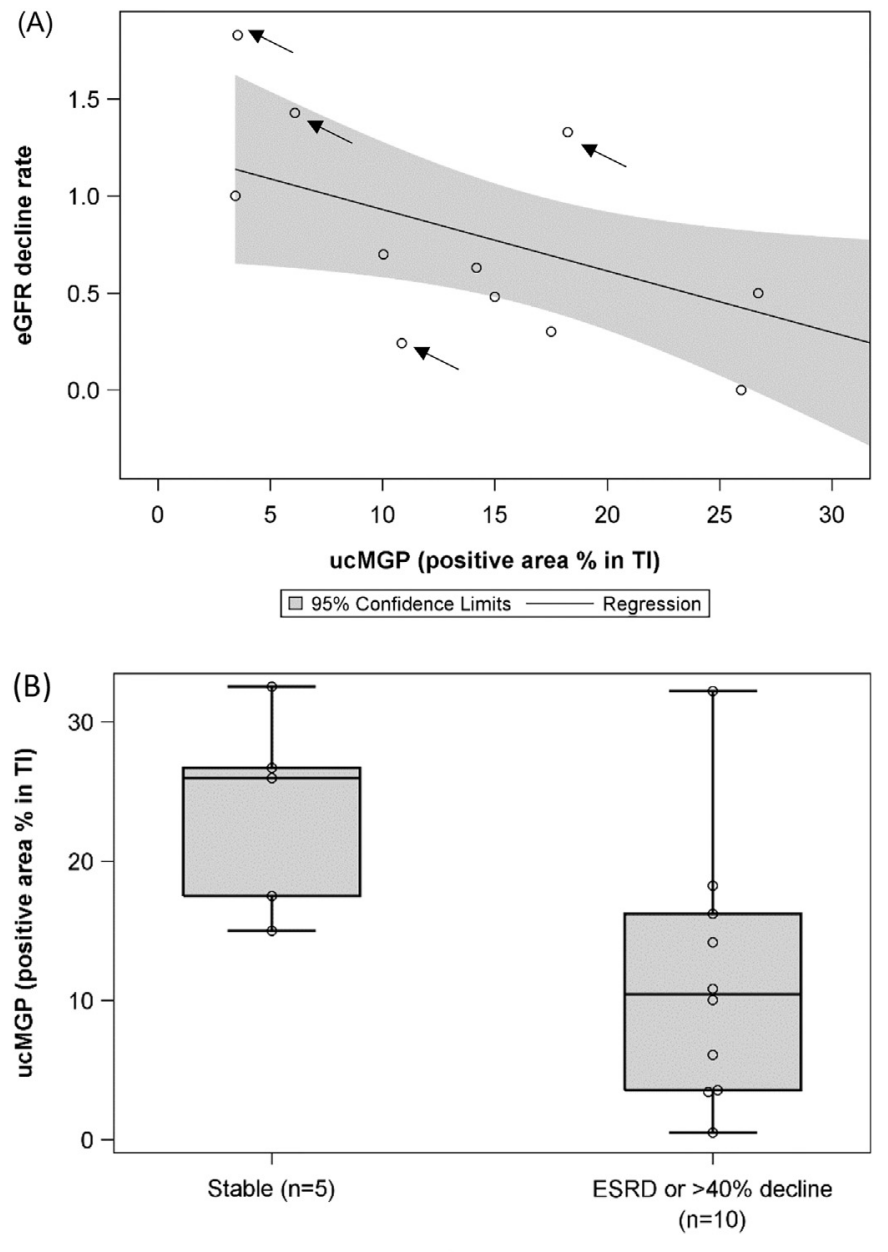

Outcome

Fig. 9. Correlation between ucMGP positive area in TI (\%) and eGFR decline rate $\left(\mathrm{mL} / \mathrm{min} / 1.73 \mathrm{~m}^{2} / \mathrm{month}\right)(\mathrm{A})$ and comparison of ucMGP positive area in TI (\%) between patients with stable renal function and patients with progressive renal disease (B).

While TI ucMGP positive area was variable even among patients with the same CKD stage (Fig. 8D), the rate of eGFR decline per month $\left(\mathrm{mL} / \mathrm{min} / 1.73 \mathrm{~m}^{2} /\right.$ month) was negatively correlated with TI ucMGP positive area (Fig. 9A, $r=-0.577, p=0.04$ ). Similarly, when TI ucMGP positive area (\%) was compared between patients who continued to have stable renal function and patients who reached ESRD or $40 \%$ decline in eGFR within 5 years, stable patients had a higher average rate of ucMGP positive areas (Fig. 9B, $23.5 \pm 7.2 \%[N=5]$ vs $11.5 \pm 9.3 \%[N=10], p=0.03)$.

\section{Discussion}

To the best of our knowledge, this is the first study that combines analyses of renal MGP gene expression in CKD in experimental animals and patients, protein localization in human kidney tissues, and correlative relationships between MGP expression and renal functional outcomes.

Renal MGP expression is increased in an animal model of progressive renal failure induced by $5 / 6 \mathrm{Nx}$. Glomerular and TI MGP expression also is increased in NEPTUNE cohort patients with glomerular disease and progressive CKD. These results are consistent with published microarray results, which show that renal MGP expression is increased in DKD patients and in ageing rats (Woroniecka et al., 2011; Hultström et al., 2012). One of our unique findings is that TI MGP expression is associated with IF/TA, ATI, and II, independent of eGFR.
Furthermore, patients with higher TI MGP had a higher hazard of ESRD $/ 40 \%$ decline in eGFR, even after adjustment of multiple covariates known as accelerators of CKD. In human atherosclerotic plaques, increased MGP expression may be a cellular adaptation to inhibit calcification. While this may be operative in renal injury, MGP may impact on other pathways in the kidney. cMGP inhibits BMP-2 (Zebboudj et al., 2002), which is an antagonist of renal IF (Yang et al., 2009). Thus, increased renal MGP may facilitate IF by interfering with the renoprotectant actions of BMP-2. Another hypothesis is that low vitamin $\mathrm{K}$ intake in this population may be causing poor carboxylation, therefore limiting the renoprotective effect of cMGP (Wei et al., 2017), even though MGP is upregulated on transcription level. Currently, the consequences of increased renal MGP expression remain unclear.

Our studies showed an inverse association between TI inactive ucMGP staining and eGFR decline rate while active cMGP or combined cMGP + ucMGP positive areas were not associated with CKD progression. This result seems inconsistent with the gene expression result, where NEPTUNE patients with higher TI MGP expression had a worse renal outcome. This discrepancy may be explained by measurement of intravascular MGP protein in addition to MGP produced locally. Rennenberg et al. demonstrated that the average renal fractional extraction of MGP was $12.8 \%$ by comparing the MGP concentrations of human renal arteries and veins (Rennenberg et al., 2008). Thus, patients with stable renal function may have more ucMGP originating from the systemic circulation. Another possible explanation is the difference in original kidney disease. This analysis of renal outcomes was performed for the combined data of 13 biopsies with DKD or FSGS, while NEPTUNE gene expression data were from patients with proteinuria without diabetes. In fact, in Fig. 9, the three patients with the highest eGFR decline rate were diabetic patients. Because the clinical course of DKD may be different from the NEPTUNE glomerular diseases, MGP expression and posttranslational protein synthesis may also be differentially affected.

This study has limitations. First, in this observational study causeand-effect relationships cannot be inferred. Elevated MGP expression in advanced CKD may be a consequence of CKD or a cause of CKD progression. Second, our histological analysis was a retrospective study using stored kidney biopsy tissues. Thus, we could not obtain circulating levels of cMGP, ucMGP, Vitamin K, protein induced in vitamin $\mathrm{K}$ absence II (PIVKA-II, ucFII, a marker of vitamin $\mathrm{K}$ deficiency), and urinary MGP at the time of the biopsy. Future studies would benefit from prospective design, assessing the correlations of these markers and the histological changes, and the renal prognosis. Finally, we used nonneoplastic kidney from cancer nephrectomies as controls and at this time, it is not known if cancers alter MGP expression or MGP protein synthesis and/or modifications.

\section{Conclusion}

This study provides clear evidence that MGP is expressed in control and diseased glomeruli and TI, with increased expression in glomerular disease. There is a negative correlation between MGP expression and eGFR, and the degree of TI MGP expression may have value as a predictor of renal outcome. Additional studies are needed to determine if the expression of renal MGP represents glomerular and tubular dedifferentiation or an injury adaptation, and if the local production of cMGP and/or ucMGP protein have any direct clinical significance in the progression or prevention of CKD.

Supplementary data to this article can be found online at https:// doi.org/10.1016/j.yexmp.2018.07.001.

\section{Acknowledgements}

The Nephrotic Syndrome Study Network Consortium (NEPTUNE), U54-DK-083912, is a part of the National Institutes of Health (NIH) Rare Disease Clinical Research Network (RDCRN), supported through a 
collaboration between the Office of Rare Diseases Research (ORDR), NCATS, and the National Institute of Diabetes, Digestive, and Kidney Diseases. Additional funding and/or programmatic support for this project has also been provided by the University of Michigan, the NephCure Kidney International and the Halpin Foundation.

Part of the data was presented in posters at Renal Research Institute 19th International Conference on Dialysis 2017, and Kidney Week 2017, the annual meeting of the American Society of Nephrology.

\section{Conflict of interest}

The authors declare that there are no conflicts of interest.

\section{Funding}

This study was supported in part by UCLA Clinical and Translational Science Institute seed grant 530693, and Cedars-Sinai CSRI Academic Pathology Award for Basic, Translational and Clinical ResearchNAST2017A. KNM was supported by a generous gift honoring the life and work of nephrologist Henry Shavelle, MD.

\section{Declarations of interest}

None.

\section{Appendix}

Members of the Nephrotic Syndrome Study Network (NEPTUNE)

NEPTUNE Enrolling Centers

Case Western Reserve University, Cleveland, OH: J Sedor*, K Dell**, M Schachere ${ }^{\#}$.

Children's Hospital, Los Angeles, CA: K Lemley*, L Whitted" ${ }^{\#}$. Children's Mercy Hospital, Kansas City, MO: T Srivastava*, C Haney\#. Cohen Children's Hospital, New Hyde Park, NY: C Sethna*, K Grammatikopoulos".

Columbia University, New York, NY: G Appel*, M Toledo\#. Emory University, Atlanta, GA: L Greenbaum*, C Wang**, B Lee ${ }^{\#}$. Harbor-University of California Los Angeles Medical Center: S Adler*, C Nast**, J La Page ${ }^{\#}$.

John H. Stroger Jr. Hospital of Cook County, Chicago, IL: A Athavale*, M Itteera ${ }^{\#}$

Johns Hopkins Medicine, Baltimore, MD: A Neu*, S Boynton ${ }^{\#}$.

Mayo Clinic, Rochester, MN: F Fervenza*, M Hogan**, J Lieske*, V Chernitskiy ${ }^{\#}$.

Montefiore Medical Center, Bronx, NY: F Kaskel*, N Kumar*, P Flynn" . NIDDK Intramural, Bethesda MD: J Kopp*, E Castro-Rubio ${ }^{\#}, \mathrm{E}$ Brede $^{\#}$.

New York University Medical Center, New York, NY: H Trachtman*, O

Zhdanova**, F Modersitzki ${ }^{\#}$, S Vento ${ }^{\#}$.

Stanford University, Stanford, CA: R Lafayette*, K Mehta ${ }^{\#}$.

Temple University, Philadelphia, PA: C Gadegbeku*, D Johnstone**; Z

Pfeffer" .

University Health Network Toronto: D Cattran*, M Hladunewich**, H

Reich**, P Ling ${ }^{\#}$, M Romano\#.

University of Miami, Miami, FL: A Fornoni*, L Barisoni*, C Bidot"

University of Michigan, Ann Arbor, MI: M Kretzler*, D Gipson*, A

Williams", R Pitter"

University of North Carolina, Chapel Hill, NC: P Nachman*, K Gibson*, S Grubbs ${ }^{\#}$, Anne Froment ${ }^{\#}$.

University of Pennsylvania, Philadelphia, PA: L Holzman*, K Meyers**,

K Kallem ${ }^{\#}$, FJ Cerecino" .

University of Texas Southwestern, Dallas, TX: K Sambandam*, E Brown***, N Johnson" ${ }^{*}$.

University of Washington, Seattle, WA: A Jefferson*, S Hingorani**, K Tuttle**\$ $^{*}$ K Klepach ${ }^{\#}$, S Dismuke ${ }^{\#}$, A Cooper ${ }^{\# \S}$.
Wake Forest University, Winston-Salem, NC: B Freedman*, JJ Lin**, M Spainhour ${ }^{\#}$, S Gray ${ }^{\#}$.

Data Analysis and Coordinating Center: M Kretzler, L Barisoni, C Gadegbeku, B Gillespie, D Gipson, B Gizinski, L Holzman, L Mariani, M Sampson, P Song, J Troost, J Zee, E Herreshoff, C Kincaid, C Lienczewski, T Mainieri, A Williams.

National Institute of Diabetes and Digestive and Kidney Diseases (NIDDK) Program Office: K Abbott, C Roy.

The National Center for Advancing Translational Sciences (NCATS) Program Office: T Urv, PJ Brooks.

*Principal Investigator; **Co-investigator; ${ }^{*}$ Study Coordinator.

Cedars-Sinai Medical Center, Los Angeles, CA.

${ }^{\S}$ Providence Medical Research Center, Spokane, WA.

\section{References}

Barisoni, L., Troost, J.P., Nast, C., et al., 2016. Reproducibility of the NEPTUNE descriptor-based scoring system on whole-slide images and histologic and ultrastructural digital images. Mod Pathol 29, 671-684.

Cozzolino, M., Dusso, A.S., Liapis, H., et al., 2002. The effects of sevelamer hydrochloride and calcium carbonate on kidney calcification in uremic rats. J Am Soc Nephrol 13, 2299-2308.

Evenepoel, P., Daenen, K., Bammens, B., et al., 2015. Microscopic nephrocalcinosis in chronic kidney disease patients. Nephrol Dial Transplant 30, 843-848.

Gadegbeku, C.A., Gipson, D.S., Holzman, L.B., et al., 2013. Design of the Nephrotic Syndrome Study Network (NEPTUNE) to evaluate primary glomerular nephropathy by a multidisciplinary approach. Kidney Int 83, 749-756.

Gimenez, L.F., Solez, K., Walker, W.G., 1987. Relation between renal calcium content and renal impairment in 246 human renal biopsies. Kidney Int 31, 93-99.

Gipson, D.S., Troost, J.P., Lafayette, R.A., et al., 2016. Complete remission in the nephrotic syndrome study network. Clin J Am Soc Nephrol 11, 81-89.

Hogan, M.C., Lieske, J.C., Lienczewski, C.C., et al., 2015. Strategy and rationale for urine collection protocols employed in the NEPTUNE study. BMC Nephrol 16, 190.

Holden, R.M., Booth, S.L., Day, A.G., et al., 2015. Inhibiting the progression of arterial calcification with vitamin K in HemoDialysis patients (iPACK-HD) trial: rationale and study design for a randomized trial of vitamin $\mathrm{K}$ in patients with end stage kidney disease. Can J Kidney Health Dis 2, 17.

Hultström, M., Leh, S., Paliege, A., Bachmann, S., Skogstrand, T., Iversen, B.M., 2012. Collagen-binding proteins in age-dependent changes in renal collagen turnover: microarray analysis of mRNA expression. Physiol Genomics 44, 576-586.

Ibels, L.S., Alfrey, A.C., Haut, L., Huffer, W.E., 1978. Preservation of function in experimental renal disease by dietary restriction of phosphate. N Engl J Med 298, 122-126.

Ibels, L.S., Alfrey, A.C., Huffer, W.E., Craswell, P.W., Weil III, R., 1981. Calcification in end-stage kidneys. Am J Med 71, 33-37.

Knapen, M.H., Braam, L.A., Drummen, N.E., Bekers, O., Hoeks, A.P., Vermeer, C., 2015 Menaquinone-7 supplementation improves arterial stiffness in healthy postmenopausal women. A double-blind randomized clinical trial. Thromb Haemost 113, 1135-1144.

Krueger, T., Schlieper, G., Schurgers, L., et al., 2013. Vitamin K1 to slow vascular calcification in haemodialysis patients (VitaVasK trial): a rationate and study protocol. Nephrol Dial Transplant 29, 1633-1638.

Kurnatowska, I., Grzelak, P., Masajtis-Zagajewska, A., et al., 2016. Plasma DesphosphoUncarboxylated Matrix Gla Protein as a Marker of Kidney Damage and Cardiovascular Risk in Advanced Stage of Chronic Kidney Disease. Kidney Blood Press Res 41, 231-239.

Lai, J.Y., Luo, J., O'Connor, C., et al., 2015. MicroRNA-21 in glomerular injury. J Am Soc Nephrol 26, 805-816.

Lau, K., 1989. Phosphate excess and progressive renal failure: the precipitation-calcification hypothesis. Kidney Int 36, 918-937.

Levey, A.S., Inker, L.A., Matsushita, K., et al., 2014. GFR decline as an end point for clinical trials in ckd: a scientific workshop sponsored by the national kidney foundation and the US Food and drug administration. Am J Kidney Dis 64, 821-835.

O'Young J, Liao Y, Xiao Y, et al. Matrix gla protein inhibits ectopic calcification by a direct interaction with hydroxyapatite crystals. J Am Chem Soc 2011;133:18406-18412

Luo, G., Ducy, P., McKee, M.D., et al., 1997. Spontaneous calcification of arteries and cartilage in mice lacking matrix GLA protein. Nature 386, 78-81.

Mariani, L.H., Martini, S., Barisoni, L., et al., 2017 Feb 27. Interstitial fibrosis scored on whole-slide digital imaging of kidney biopsies is a predictor of outcome in proteinuric glomerulopathies. Nephrol Dial Transplant. https://doi.org/10.1093/ndt/gfw443. Epub ahead of print.

Proudfoot, D., Skepper, J.N., Shanahan, C.M., Weissberg, P.L, 1998. Calcification of human vascular cells in vitro is correlated with high levels of matrix Gla protein and low levels of osteopontin expression. Arterioscler Thromb Vasc Biol 18, 379-388.

Rennenberg, R.J., Schurgers, L.J., Vermeer, C., et al., 2008. Renal handling of matrix Glaprotein in humans with moderate to severe hypertension. Hypertens Res 31 , 1745-1751.

Schmid, H., Boucherot, A., Yasuda, Y., et al., 2006. Modular activation of nuclear factorkappaB transcriptional programs in human diabetic nephropathy. Diabetes 55, 2993-3003.

Schurgers, L.J., Spronk, H.M., Skepper, J.N., et al., 2007. Post-translational modifications regulate matrix Gla protein function: importance for inhibition of vascular smooth 
muscle cell calcification. J Thromb Haemost 5, 2503-2511.

Schurgers, L.J., Barreto, D.V., Barreto, F.C., et al., 2010. The circulating inactive form of matrix gla protein is a surrogate marker for vascular calcification in chronic kidney disease: a preliminary report. Clin J Am Soc Nephrol 5, 568-575.

Schurgers, L.J., Uitto, J., Reutelingsperger, C.P., 2013. Vitamin K-dependent carboxylation of matrix Gla-protein: a crucial switch to control ectopic mineralization. Trends Mol Med 19, 217-226.

Schurgers, L.J., Teunissen, K.J., Knapen, M.H., et al., 2015. Novel conformation-specific antibodies against matrix gamma-carboxyglutamic acid (Gla) protein:

Undercarboxylated matrix Gla protein as marker for vascular calcification. Arterioscler Thromb Vasc Biol 25, 1629-1633.

Shanahan, C.M., Cary, N.R., Metcalfe, J.C., Weissberg, P.L., 1994. High expression of genes for calcification regulating proteins in human atherosclerotic plaques. J Clin Invest 93, 2393-2402.

Viegas, C.S.B., Costa, R.M., Santos, L., et al., 2017. Gla-rich protein function as an antiinflammatory agent in monocytes/macrophages: Implications for calcification-related chronic inflammatory diseases. PLoS One 12, e0177829.

Wei, F.F., Drummen, N.E., Schutte, A.E., et al., 2016a. Vitamin K dependent protection of renal function in multi-ethnic population studies. EBioMed 4, 162-169.

Wei, F.F., Drummen, N.E., Thijs, L., et al., 2016b. Vitamin-K-Dependent Protection of the
Renal Microvasculature: Histopathological Studies in Normal and Diseased Kidneys. Pulse (Basel). 4, 85-91.

Wei, F.F., Trenson, S., Thijs, L., et al., 2017 Aug 25. Desphospho-uncarboxylated matrix Gla protein is a novel circulating biomarker predicting deterioration of renal function in the general population. Nephrol Dial Transplant. https://doi.org/10.1093/ndt/ gfx258. Epub ahead of print.

Wei, F.F., Trenson, S., Monney, P., et al., 2018a. Epidemiological and histological findings implicate matrix Gla protein in diastolic left ventricular dysfunction. PLoS One. e0193967, 13.

Wei, X., Wu, W., Li, L., et al., 2018b. Bone Morphogenetic Proteins 2/4 Are Upregulated during the Early Development of Vascular Calcification in Chronic Kidney Disease. Biomed Res Int. 2018, 8371604.

Woroniecka, K.I., Park, A.S., Mohtat, D., Thomas, D.B., Pullman, J.M., Susztak, K., 2011. Transcriptome analysis of human diabetic kidney disease. Diabetes 60, 2354-2369.

Yang, Y.L., Liu, Y.S., Chuang, L.Y., et al., 2009. Bone morphogenetic protein-2 antagonizes renal interstitial fibrosis by promoting catabolism of type I transforming growth factor-beta receptors. Endocrinology 150, 727-740.

Zebboudj, A.F., Imura, M., Bostrom, K., 2002. Matrix GLA Protein, a regulatory protein for bone morphogenetic protein-2. J Biol Chem 277, 4388-4394. 